\title{
Concurrent schedules of wheel-running reinforcement: Choice between different durations of opportunity to run in rats
}

\author{
TERRY W. BELKE \\ Mount Allison University, Sackville, New Brunswick, Canada
}

\begin{abstract}
How do animals choose between opportunities to run of different durations? Are longer durations preferred over shorter durations because they permit a greater number of revolutions? Are shorter durations preferred because they engender higher rates of running? Will longer durations be chosen because running is less constrained? The present study reports on three experiments that attempted to address these questions. In the first experiment, five male Wistar rats chose between 10-sec and 50-sec opportunities to run on modified concurrent variable-interval (VI) schedules. Across conditions, the durations associated with the alternatives were reversed. Response, time, and reinforcer proportions did not vary from indifference. In a second experiment, eight female Long-Evans rats chose between opportunities to run of equal ( $30 \mathrm{sec}$ ) and unequal durations (10 sec and $50 \mathrm{sec}$ ) on concurrent variable-ratio (VR) schedules. As in Experiment 1, between presentations of equal duration conditions, 10-sec and 50-sec durations were reversed. Results showed that response, time, and reinforcer proportions on an alternative did not vary with reinforcer duration. In a third experiment, using concurrent VR schedules, durations were systematically varied to decrease the shorter duration toward 0 sec. As the shorter duration decreased, response, time, and reinforcer proportions shifted toward the longer duration. In summary, differences in durations of opportunities to run did not affect choice behavior in a manner consistent with the assumption that a longer reinforcer is a larger reinforcer.
\end{abstract}

What is the relationship between duration of access to run and the value of an opportunity to run? Is a longer duration of greater value because it affords a greater number of revolutions? Or is a shorter duration of greater value because it engenders a higher wheel-running rate? In the present study, rats were exposed to concurrent schedules of wheel-running reinforcement to assess choice between reinforcers of different durations.

If one likens duration of an opportunity to run to duration of access to food, then longer equals larger. As duration of access to food increases, the amount of food consumed increases (Epstein, 1981). Similarly, as the duration of an opportunity to run increases, the number of revolutions increases (Belke, 1997; Belke \& Hancock, 2003). This approach likens a revolution to a small bit of food. Bonem and Crossman's (1988) review of the effects of reinforcer magnitude showed that on choice procedures, larger reinforcers are consistently preferred. Thus, if longer equals larger, the longer reinforcer should be preferred.

A problem for this prediction is that it is not supported by findings from studies involving simple schedules of wheel-running reinforcement. On simple schedules of re-

This research was supported by Grant 0GP0170022 from the Natural Sciences and Engineering Research Council of Canada. Correspondence regarding this article should be sent to T. W. Belke, Department of Psychology, Mount Allison University, Sackville, NB, E4L 1C7 Canada (e-mail: tbelke@mta.ca). inforcement, a response-strength perspective predicts that as reinforcement magnitude increases, overall and local response rates should increase, and postreinforcement pause (PRP) duration should decrease. However, when the effect of wheel-running reinforcer duration was investigated on tandem fixed-ratio (FR) 1 variable-interval (VI) 30 -sec schedules, the opposite occurred. PRP duration increased, and overall and local response rates decreased as wheelrunning reinforcer duration increased from 30 to $120 \mathrm{sec}$ (Belke, 1997). Similarly, studies of reinforcer magnitude with food reinforcement using simple schedules have produced inconsistent findings (Bonem \& Crossman, 1988). Overall response rates have been shown to increase (Harzem, Lowe, \& Priddle-Higson, 1978; Hutt, 1954; Jenkins \& Clayton, 1949; Meltzer \& Brahlek, 1968, 1970; Reed \& Wright, 1988; Stebbins, Mead, \& Martin, 1959), decrease (Lowe, Davey, \& Harzem, 1974; Priddle-Higson, Lowe, \& Harzem, 1976; Staddon, 1970), or not be affected by reinforcer magnitude (Catania, 1963; Keesey \& Kling, 1961; Powell, 1969). Likewise, local rates increased (Harzem et al., 1978; Lowe et al., 1974; Reed \& Wright, 1988), decreased (Reed, 1991; Staddon, 1970), or did not vary systematically (Kliner, Lemaire, \& Meisch, 1988; Lowe et al., 1974; Powell, 1969; Priddle-Higson et al., 1976). PRPs decreased (Powell, 1969) and increased (Lowe et al., 1974; Reed, 1991; Staddon, 1970).

On simple schedules, local leverpressing rate varied with wheel-running rate rather than revolutions. Local leverpressing and wheel-running rates decreased, as du- 
ration increased (Belke, 1997). Because the value of a reinforcer is indexed by the rate of responding that it maintains, this result suggests that shorter durations were of greater value, and the covariation between wheel-running and local leverpressing rates suggests that rate of running may play a role in the value of an opportunity to run. Based on these findings, one would predict that on concurrent schedules of wheel-running reinforcement, shorter durations, if they generate higher wheel-running rates, would be preferred over longer durations.

The suggestion that rate of running engendered by an opportunity to run may play a role in its value points to a problem with considering the revolution as the unit of value. If rate does not matter, then 100 revolutions run in $60 \mathrm{sec}$ should be equivalent in value to 100 revolutions run in $600 \mathrm{sec}$. If rate does matter, then the former would be of greater value than the latter. Similarly, the amount of food consumed within a given duration of access depends on the rate of consumption.

It is also important to note that the covariance between local leverpressing and wheel-running rates is not simply an artifact of differential parsing of a declining wheelrunning rate. Wheel-running rate within a reinforcement period is typically higher earlier in the interval and declines as the interval elapses (Belke \& Hancock, 2003; Belke \& McLaughlin, 2005). This pattern means that wheel-running rate will vary with reinforcer duration simply because shorter durations represent higher rates earlier in the interval, whereas longer durations include both the higher earlier and the lower later rates. However, when wheel-running rates are measured across different reinforcer durations (see, e.g., Belke \& Hancock, 2003), rates within shorter durations (e.g., a 15-sec reinforcer) differ from those observed over the same duration within longer reinforcers (e.g., the first $15 \mathrm{sec}$ of a 90 -sec reinforcer). Shorter durations engender higher rates.

Response deprivation and behavior regulation theories (Allison, 1993; Timberlake \& Allison, 1974) provide an alternative to response-strength theory with respect to understanding the effects of wheel-running reinforcer duration. According to these theories, under unconstrained conditions, an animal has a baseline level of running. Restricting access to running leads the animal to engage in a less restricted behavior (e.g., leverpressing) that provides access to running. From this perspective, the duration of the opportunity to run represents a constraint on running. As duration decreases, the constraint on running increases, as does its effectiveness at generating the operant behavior that produces it. This would account for the inverse relationship between duration and local leverpressing rates on simple schedules (Belke, 1997). On concurrent schedules, in which an animal chooses between different durations, one would expect an animal to prefer the longer duration because it is less constrained and allows the animal to run closer to its unconstrained baseline level.

In summary, if wheel-running reinforcers of different durations differ in value, then on concurrent schedules with different reinforcer durations, the higher valued alternative should be preferred. If longer is larger, and the revolution is the unit of value, then the longer duration alternative should be preferred, because it allows for a greater number of revolutions to occur. Similarly, the longer duration may be preferred because it is less constrained. In contrast, if the value of an alternative is related to the rate at which running occurs, then the shorter duration should be preferred, because it generates higher rates of running.

\section{EXPERIMENT 1}

Rats were exposed to equal concurrent VI schedules of wheel-running reinforcement with different reinforcer durations. The animals were first exposed to two different durations to determine if there was any evidence of systematic choice for one alternative. Subsequently, the durations were reversed, to counter side bias and to determine whether or not choice behavior would follow the change in duration.

The concurrent VI schedules were modified so that the intervals on both schedules would stop timing when a reinforcer was initiated on either alternative and not begin to time again until the first response on either alternative following the termination of the reinforcer. This modification was necessary for the following reasons. Wheel running generates longer PRPs than conventional reinforcers do, and PRPs remain long even when the schedule requirement is variable and of short duration. On a standard VI schedule, intervals would time out during these long PRPs and lead the schedule to be experienced as something other than that which was programmed (e.g., continuous reinforcement). Furthermore, because PRP duration varies with reinforcer duration, the difference in pause duration generated by the different durations would differentially affect the operation of concurrent-interval schedules. However, modifying interval schedules to be response initiated produces ratio-like changes in the pattern of responding generated by the schedule (Shull, 1970).

Durations of 10 and $50 \mathrm{sec}$ were chosen because previous research with simple schedules of wheel-running reinforcement (Belke, 1997; Belke \& Dunbar, 1998; Belke \& Hancock, 2003) suggested that these durations would generate different leverpressing and wheel-running rates.

\section{Method}

Subjects. Five male Wistar rats obtained from Charles River Breeding Laboratories, St. Constant, Quebec, served as subjects. The rats had previously participated in Belke and Belliveau's (2001) study of choice on concurrent schedules of wheel-running reinforcement. When not in the experimental apparatus, the rats were individually housed in standard polycarbonate cages $(48 \mathrm{~cm} \times 27 \mathrm{~cm} \times$ $22 \mathrm{~cm}$ ) in a colony room maintained at $20^{\circ} \mathrm{C}$ with a $12: 12$-h light: dark cycle (lights on at 0800). The subjects were maintained at a target weight that was approximately $85 \%$ of a free-feeding body weight taken when the weights of the rats rose just above $400 \mathrm{~g}$ (i.e., adult weight). As a result, target weights varied around $335 \mathrm{~g} \pm 10 \mathrm{~g}$. Distilled water was freely available in the home cages.

Apparatus. The subjects were tested in two Wahmann activity wheels without side cages. The diameters of the wheels were $35.5 \mathrm{~cm}$. Each wheel was located in a sound-attenuating shell equipped with a fan (for ventilation and to mask extraneous noise). A solenoidoperated brake was attached to the base of each wheel. When the 
solenoid was activated, a rubber tip attached to a metal shaft made contact with the outer rim of the wheel and brought the wheel to a stop. A microswitch attached to the wheel frame recorded wheel revolutions. Lights (24-V DC) mounted on the sides of the wheel frame served to illuminate the inside of the wheel chamber.

Velcro was used to attach a Plexiglas panel holding two response levers, 2 LED stimulus lights, and a solution receptacle to the wheel frame. The levers were $1.5 \mathrm{~cm}$ wide and extended $2 \mathrm{~cm}$ out from the surface of the panel. The force required to activate a lever ranged between 31 and $33 \mathrm{~N}$. The levers were located $13 \mathrm{~cm}$ from the base of the panel and were separated by $4.5 \mathrm{~cm}$. A solution receptacle was located in the space between the two levers. Yellow LED stimulus lights were located $0.7 \mathrm{~cm}$ above each lever. When the panel was attached to the wheel, the levers extended through the $7 \mathrm{~cm} \times 9 \mathrm{~cm}$ opening to the wheel. IBM personal computers, interfaced to the wheels through the parallel port, controlled the experimental events and the recording of data.

Procedure. The procedure used to train wheel running as a reinforcing consequence for leverpressing is reported in detail in Belke and Belliveau (2001). A brief version follows. Rats were first provided the opportunity to run for $30 \mathrm{~min}$ each day. After 10 days, leverpress training in standard operant-conditioning chambers occurred following $30 \mathrm{~min}$ of running. Leverpressing was shaped using the method of successive approximation. When animals were successfully trained to leverpress, sessions in the operant chamber ceased, and the opportunity to run for $60 \mathrm{sec}$ in running wheels equipped with retractable levers was made contingent upon a single leverpress. Fixed-ratio (FR) 1, variable-ratio (VR) 3, VR 5, VR 9, and VR 15 schedules were programmed to occur, each for four sessions.

Following this training, the animals were transferred to the wheels equipped with Plexiglas panels (described in the Apparatus section). Animals were first exposed to sessions with only the left or the right lever operative. The stimulus light above the operative lever was illuminated, the schedule was VI $30 \mathrm{sec}$, and the reinforcer was the opportunity to run for $15 \mathrm{sec}$. When the programmed interval elapsed and a response occurred on the operative lever, the stimulus light was extinguished, the brake was released, and the lights at the side of the wheel were illuminated. After $15 \mathrm{sec}$, the brake was asserted, the side lights were extinguished, and the stimulus light was illuminated. Each animal was exposed to 5 sessions with the left lever operative and then 5 sessions with the right lever operative. Following this, the animals were exposed to a concurrent VI 30-sec VI 30-sec schedule for 10 sessions before commencing the series of concurrent VI schedules used in the Belke and Belliveau (2001) study.

For the present study, which followed completion of Belke and Belliveau's (2001) study, five rats were exposed to concurrent VI 60 -sec schedules. For one alternative, the reinforcer was the opportunity to run for $10 \mathrm{sec}$; for the other, the opportunity to run lasted $50 \mathrm{sec}$. A 2-sec changeover delay was in effect. This was the period of time that had to elapse after an animal changed over between alternatives before a reinforcer was delivered. Sessions terminated after $45 \mathrm{~min}$. After 50 sessions, reinforcer durations were reversed, and another 50 sessions were conducted. For two of the rats (TL3, TL26), the 10-sec reinforcer duration was on the left in the first condition and on the right in the reversal condition. For the remaining three rats (TL1, TL11, TL16), this arrangement was reversed.

Leverpresses to, time spent on, changeovers to, and reinforcers obtained from each alternative were recorded during each session. In addition, PRPs following each reinforcer and revolutions during each reinforcer were recorded. Data from the last 10 sessions of each condition were used for data analysis.

\section{Results}

Figure 1 depicts response, time, and reinforcer proportions for the alternative leading to the 10 -sec reinforcer duration in both conditions for each rat and for the group. Time proportions were based on time spent responding on each alternative, with PRPs excluded. In general, values varied about indifference (i.e., .5). For some rats (e.g., TL1, TL26) this variance appears to be a function of side bias. That is, the proportion for the longer alternative was greater than .5 when it was on one side and less than .5 when it was on the other.

Proportions were assessed for systematic preference by averaging proportions across the two conditions and testing the result against indifference. Collapsing across the conditions should have had the effect of averaging out side bias. Mean response, time, and reinforcer proportions were $.47, .48$, and .49 , respectively. The $t$ tests revealed that response, time, and reinforcer proportions were not significantly different from indifference $[t(4)=-1.63$, -1.11 , and -1.95 , respectively, all $p \mathrm{~s}>.05]$.

Median PRPs varied with reinforcer duration. Pauses following the 50 -sec opportunity to run were longer. On average, the median pause following a 50-sec opportunity to run was $65.45 \mathrm{sec}$, whereas the median pause following a 10 -sec opportunity was $23.87 \mathrm{sec}$. A paired $t$ test confirmed that pauses were significantly longer following the longer reinforcer $[t(4)=-3.98, p<.05]$.

Wheel-running rate also differed with duration. Mean wheel-running rates for the 10 -sec and 50 -sec durations were 42.02 and $29.53 \mathrm{rpm}$, respectively. A paired $t$ test showed that the running rate was higher at the shorter duration $[t(4)=10.60, p<.05]$.

\section{Discussion}

Choice was not affected by the difference in duration. The longer duration reinforcer was not preferred, as would be predicted if magnitude varied with duration or because it was less constrained. Nor was the shorter duration preferred, as would be predicted from the results with simple schedules (Belke, 1997). Furthermore, the shorter duration was not preferred even though wheel-running rates were higher on this alternative. However, because wheelrunning rates were not measured within the reinforcer interval, it is not possible to determine whether or not the differences observed with simple schedules (Belke \& Hancock, 2003) were present with concurrent schedules.

\section{EXPERIMENT 2}

Concurrent-interval schedules of equal duration tend to produce indifference between alternatives due to the operation of the schedules. In contrast, concurrent-ratio schedules with equivalent ratio requirements yield a wide range of distributions (see, e.g., Herrnstein \& Loveland, 1975). Also, ratio schedules do not need to be modified to accommodate long PRPs or asymmetry in PRPs. For these reasons, rats were exposed to concurrent VR schedules of wheel-running reinforcement using the same reinforcer durations as in Experiment 1, to assess the effect of different durations on choice.

\section{Method}

Subjects. Eight female Long-Evans rats obtained from Charles River Breeding Laboratories, St. Constant, Quebec, participated in 


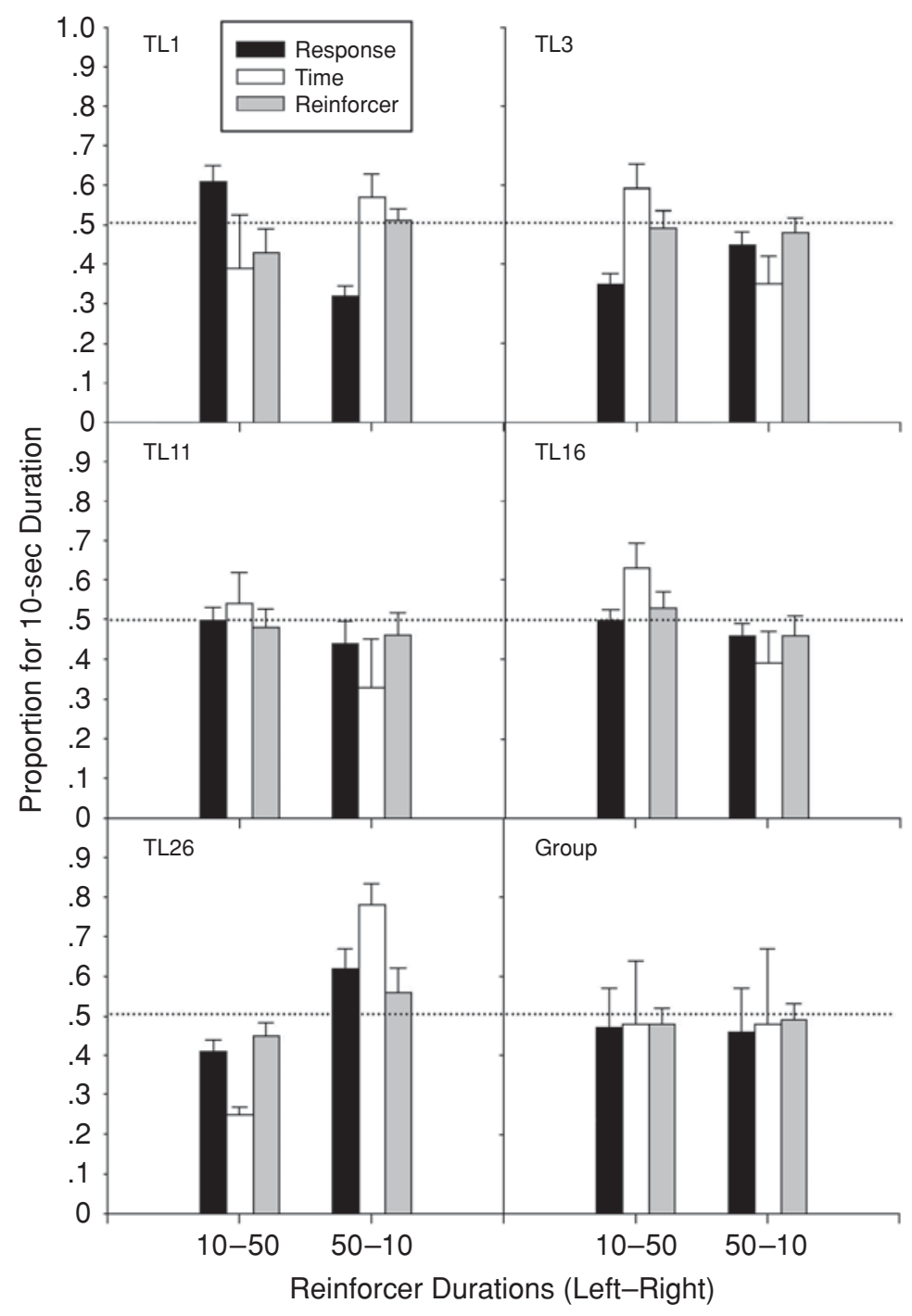

Figure 1. Mean response, time, and reinforcer proportions for the 10-sec alternative in each condition for each animal and the group. Standard errors are depicted.

this experiment. Before participating in the present study, the rats had been shaped to press a lever in a standard operant-conditioning chamber by students in a Conditioning course. All other conditions were the same as those described in Experiment 1, with the exception that the animals were maintained at a target body weight of $260 \pm 10 \mathrm{~g}$.

Apparatus. The apparatus was the same as that described in Experiment 1, with the exception that two additional wheels (Lafayette Instruments) equipped with Plexiglas panels were used.

Procedure. Training the animals to press a lever to produce an opportunity to run followed the procedure described in Experiment 1 , with the exception that the animals were not trained to press a lever in a standard operant-conditioning chamber.

Following their training, all the animals were placed on concurrent VR 5 schedules with 30-sec reinforcer durations on each alternative. Sessions terminated after $1 \mathrm{~h}$. After 35 sessions, the reinforcer durations were changed to $10 \mathrm{sec}$ and $50 \mathrm{sec}$. For half the animals, the 10-sec duration was associated with the left lever (QT7, QT12, QT16, and QT19); for the other half, it was associated with the right lever (QT6, QT17, QT19, and QT20). After 35 sessions, the dura- tions were reversed. Finally, after 35 sessions, the durations were changed back to $30 \mathrm{sec}$ on each alternative for 35 sessions.

Dependent measures were the same as those described in Experiment 1 . Data from the last 5 sessions in each condition were analyzed.

\section{Results}

Figure 2 depicts response, time, and reinforcer proportions for a given alternative as a function of the reinforcer duration associated with that alternative for each animal and the group. No systematic changes in response, time, or reinforcer proportions on an alternative occurred as a function of the reinforcer duration associated with that alternative. When the duration on the alternative was changed from 30 to $50 \mathrm{sec}$, response proportions increased (QT6, QT7, QT9, and QT19), decreased (QT12 and QT17), and remained relatively unchanged (QT16 and QT20). When 


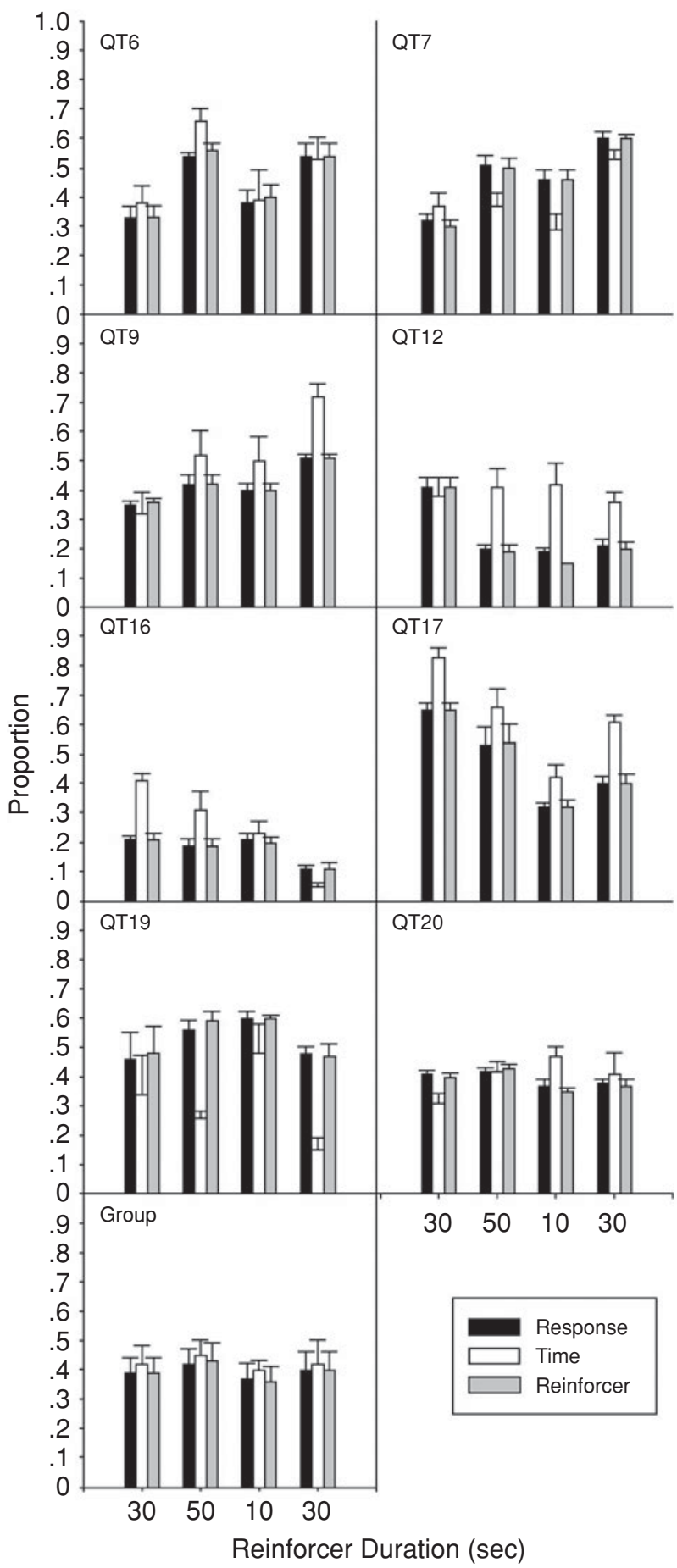

Figure 2. Mean response, time, and reinforcer proportions for an alternative as a function of the reinforcer duration associated with that alternative for each animal and the group. Standard errors are depicted.

the duration on that alternative was then changed from $50 \mathrm{sec}$ to $10 \mathrm{sec}$, response proportions decreased (QT6, QT7, QT17, and QT20) or remained unchanged (QT9, QT12, QT16, and QT19). Finally, when the duration on this alternative was increased from $10 \mathrm{sec}$ to $30 \mathrm{sec}$, response proportions increased (QT6, QT7, QT9, QT12, and QT17), decreased (QT16 and QT19), or remained unchanged (QT20).

Response proportions were assessed for systematic choice by averaging proportions across the two 30 -sec conditions [paired $t(7)=-.17$, n.s.] and assessing the effect of duration using a repeated measures ANOVA. The ANOVA showed that response proportions on an alternative were not affected by the duration of the associated wheel-running period $[F(2,14)=1.66$, n.s.].

Time proportions, although differing from response proportions, also showed no systematic variation with duration. When duration changed from 30 to $50 \mathrm{sec}$, time on the alternative increased (QT6, QT9, and QT20), decreased (QT16, QT17, and QT19), and remained unchanged (QT7 and QT12). When duration changed from 50 to $10 \mathrm{sec}$, time increased (QT19 and QT20), decreased (QT6, QT7, QT16, and QT17), and remained unchanged (QT9 and QT12). Finally, when duration increased from 10 to $30 \mathrm{sec}$, time increased (QT6, QT7, QT9, and QT17) or decreased (QT12, QT16, QT19, and QT20). Proportions across the two 30-sec conditions were averaged [paired $t(7)=-.02$, n.s.], and an ANOVA revealed no effect of duration on time proportions $[F(2,14)=.54$, n.s. $]$.

On average, the median pauses following 10-, 30-, and 50 -sec opportunities to run were $8.76,17.47$, and $22.04 \mathrm{sec}$, respectively. A repeated measures ANOVA revealed a significant effect of duration on median pause time $[F(2,14)=9.66, p<.01]$.

For most rats, wheel-running rates systematically decreased as duration increased. Mean wheel-running rates for the 10-, 30-, and 50-sec durations were 43.60, 37.38, and $34.00 \mathrm{rpm}$, respectively. A repeated measures ANOVA revealed a significant effect of duration on wheel-running rate $[F(2,14)=54.36, p<.001]$.

\section{Discussion}

Using concurrent VR rather than modified concurrent VI schedules did not change the result. Behavior allocated to an alternative did not vary with reinforcer duration. Neither the longer nor the shorter duration was preferred. Differences in PRP duration and wheel-running rates observed in Experiment 1 were replicated. As duration increased, median PRP duration increased, and wheelrunning rates decreased.

\section{EXPERIMENT 3}

In Experiments 1 and 2, differences in the duration of an opportunity to run had no systematic effect on choice between alternatives. However, it is logical to assume that as the duration of opportunity to run approaches $0 \mathrm{sec}$ on one of the alternatives, animals will not remain indifferent between short and long durations. At the extreme, when the duration on the shorter alternative is $0 \mathrm{sec}$, responding on that alternative will be on extinction, and response allocation should decrease. Consequently, in this third experiment, starting with $10-\mathrm{sec}$ and $50-\mathrm{sec}$ reinforcers, 
the duration of the shorter alternative was progressively shortened across conditions, to observe the effect on choice between durations. Time removed from the shorter alternative was added to the longer alternative so that total running time across reinforcers remained $60 \mathrm{sec}$.

\section{Method \\ Subjects. The animals used in Experiment 2 participated in Ex- periment 3.}

Apparatus. The apparatus was the same as the one described in Experiment 2.

Procedure. Experiment 3 followed Experiment 2. All animals began on concurrent VR 5 schedules of wheel-running reinforcement with reinforcer durations of 10 and $50 \mathrm{sec}$. For half the animals, the 10-sec duration was on the left alternative; for the other half, it was on the right. Sessions terminated after $1 \mathrm{~h}$. A changeover requirement was introduced, to diminish any effect of the reinforcer on the behavior of switching between the alternatives. Some unpublished data from our laboratory suggested that higher rates of changing over between alternatives were associated with lower sensitivity to the difference in ratio requirements between alternatives. When an animal changed over between alternatives, at least two responses were required to obtain a reinforcer on an alternative. Each condition in the present study was in effect for 35 sessions.

In successive conditions, the duration of the shorter reinforcer was decreased, whereas the sum of the durations across the two alternatives remained constant at $60 \mathrm{sec}$. This produced the following pairs of durations: $50-10,55-5,57.5-2.5,58.75-1.25$, and $59.5-0.5 \mathrm{sec}$. In the final condition, the durations associated with the two alternatives were switched. That is, the alternative that led to a $0.5 \mathrm{sec}$ opportunity to run was changed to $59.5 \mathrm{sec}$, and vice versa.

Dependent measures were the same as those described for Experiment 2 .

\section{Results}

Figure 3 shows the response, time, and reinforcer proportions for the shorter duration alternative as a function of the duration of that alternative for each rat and the group. QT7 died before completing the final condition. In general, as duration on the shorter alternative decreased, response and time allocation to, and reinforcers obtained from that alternative decreased. In the initial condition, although there were considerable individual differences, on average, response and time allocations were close to indifference. As the duration of the shorter alternative decreased, responses and time shifted away from the shorter alternative toward the longer alternative. This systematic shift in choice is apparent for each animal, regardless of whether the animal began with an allocation strongly oriented toward the long duration (QT17 and QT19), the short duration (QT12, QT16, and QT20), or between these extremes (QT6, QT7, and QT9). A series of paired $t$ tests against indifference revealed that response allocation toward the longer duration was not greater than indifference until the shorter duration was $2.5 \sec [t(7)=2.07, p<$ .05 , one-tailed]. In the final condition, response and time allocation followed the reversal in durations.

An examination of individual differences in how animals responded to the shift from equal durations in the last condition of Experiment 2 to unequal durations (10 sec and $50 \mathrm{sec}$ ) in the first condition of Experiment 3 suggests two different responses. Rats with a bias toward the

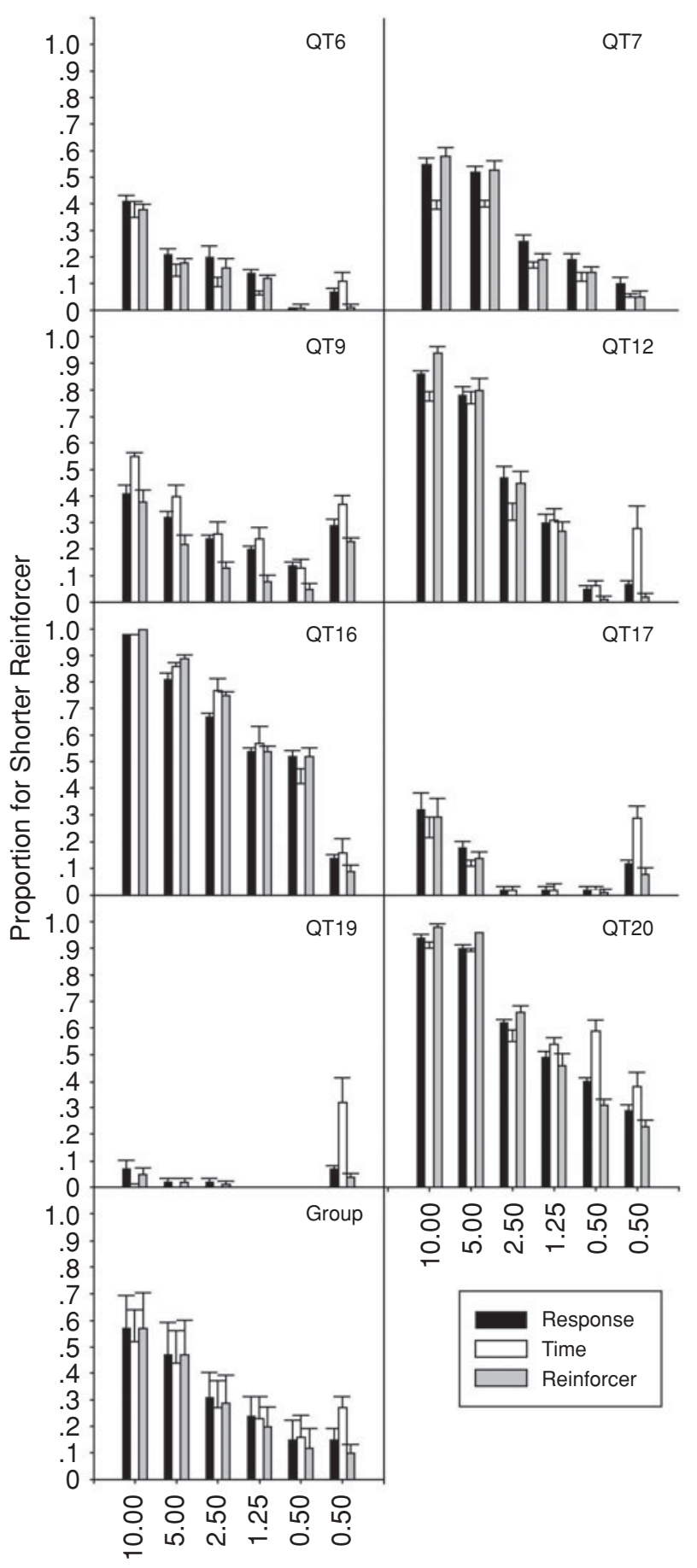

Duration of the Shorter Reinforcer (sec)

Figure 3. Mean response, time, and reinforcer proportions for the shorter duration alternative as a function of the duration associated with that alternative for each animal and the group. Standard errors are depicted.

alternative in which duration was decreased from 30 to $10 \mathrm{sec}$ markedly increased responding on this alternative, whereas responding to the nonbiased alternative was relatively unaffected. As a result, total responses allocated 
to the two alternatives increased markedly. For QT12, QT16, and QT20, responses allocated to the biased alternative changed from 224 to 488 responses, from 241 to 690 responses, and from 171 to 517 responses, respectively. In contrast, responses on the unbiased alternative that changed from 30 to $50 \mathrm{sec}$ increased modestly or decreased (58 to 76 responses, 30 to 17 responses, and 104 to 31 responses, respectively). The net effect was an increase in the already strong relative response allocation to the shorter alternative.

In contrast, rats that did not appear to have a strong bias toward either alternative (i.e., QT6, QT9, QT17, and QT19) reallocated responses toward the 50-sec duration without increasing total responses allocated. For the equal duration condition, total responses allocated were 260 , 262,242 , and 183 , respectively. For the unequal duration condition, total responses were $262,248,232$, and 154 , respectively. Although these four rats shifted their allocation to the longer alternative when durations changed to begin Experiment 3, they did not all do so when durations were similarly changed at the beginning of Experiment 2. This inconsistency weakens the conclusion that in the absence of a response bias, animals show a preference for the longer alternative.

To assess whether or not the changeover requirement had any effect, response proportions for the 50 -sec alternative in the first condition of Experiment 3 were compared with response proportions for the 50 -sec alternative in Experiment 2, in which the 50-sec alternative was on the same alternative as in Experiment 3. That is, for QT6, QT7, QT9, and QT19, the 50-sec alternative was on the same alternative in the third condition of Experiment 2. For QT12, QT16, QT17, and QT20, the 50-sec alternative was on the same alternative in the second condition of Experiment 2. The average response proportion for the 50 -sec alternative in the first condition of Experiment 3, with the changeover requirement in effect, was .43. The average response proportion for the 50 -sec alternative with this alternative at the same location in Experiment 2 was .43.

Table 1 shows the obtained ratio requirements (responses/reinforcers) for every condition in Experi- ment 3 except the reversal condition. The changeover requirement could affect the experienced ratio requirement if an animal repeatedly changed over to an alternative, made a single response, and then changed back. In this case, the experienced ratio requirement would be greater than the programmed requirement of 5 responses, on average. Another source of variance in the obtained ratio requirement is the number of obtained reinforcers. When the number of obtained reinforcers is less than the number of schedule values that comprise the programmed schedule, the obtained ratio requirement will deviate from the programmed value. However, the value will never be greater than the largest ratio requirement (i.e., 16 for the VR 5 schedule used in the present study). Table 1 shows obtained ratios greater than 16 responses for QT9 $(17.57=$ 24.6 responses $/ 1.4$ reinforcers $)$ and QT12 $(16.5=6.60$ responses $/ 0.4$ reinforcers) on the 0.5 -sec alternative in the $0.5-59.5 \mathrm{sec}$ condition and for QT16 $(87.00=17.4$ responses/0.2 reinforcers) and QT20 (17.44 $=31.40$ responses/1.8 reinforcers) on the 50 -sec alternative in the $10-50 \mathrm{sec}$ condition. In these conditions, the obtained ratios suggest that these rats were making single responses on these alternatives between changeovers, and as a consequence, increased the experienced ratio requirements on these alternatives. Did this affect preference between the alternatives? In each case, the larger ratio is on the alternative that was strongly nonpreferred; however, for QT16 and QT20, the larger ratios occurred on the longer alternative, which came to be preferred as the duration of the shorter alternative decreased. If the ratios determined preference, the difference in ratios for these animals favored the shorter, not the longer, alternative. All other values that deviated from an average close to 5 , with one exception, were conditions in which the obtained ratio requirement was less than 16, and fewer than 10 reinforcers were obtained. The one exception is the value of 10.58 (132.6/12.2) on the 55-sec alternative for QT16.

\section{Discussion}

In the initial condition, as previously observed in Experiments 1 and 2, behavior allocation did not favor either the 10 -sec or the 50 -sec alternative. However, as

Table 1 Obtained Ratio Requirements (Responses/Reinforcers) for Each Alternative in the 10-50, 5-55, 2.5-57.5, 1.25-58.75, and 0.5-59.5 sec Conditions for Each Animal

\begin{tabular}{ccccccccccc}
\hline & \multicolumn{10}{c}{ Reinforcer Duration $(\mathrm{sec})$} \\
\cline { 2 - 12 } Rat & 10 & 50 & 5 & 55 & 2.5 & 57.5 & 1.25 & 58.75 & 0.5 & 59.5 \\
\hline QT6 & 6.03 & 5.29 & 6.03 & 5.05 & 6.67 & 4.94 & 6.25 & 5.08 & - & 5.07 \\
QT7 & 5.52 & 6.12 & 5.59 & 5.70 & 7.97 & 5.30 & 7.56 & 5.28 & 10.75 & 5.12 \\
QT9 & 6.97 & 6.03 & 9.35 & 5.72 & 11.30 & 5.40 & 15.08 & 5.12 & 17.57 & 5.24 \\
QT12 & 5.22 & 14.04 & 5.22 & 6.22 & 5.55 & 5.27 & 6.12 & 5.35 & 16.50 & 4.85 \\
QT16 & 5.03 & 87.00 & 5.25 & 10.87 & 5.52 & 8.07 & 6.66 & 6.82 & 6.71 & 6.58 \\
QT17 & 6.02 & 5.17 & 6.96 & 5.13 & - & 4.99 & - & 4.89 & - & 4.99 \\
QT19 & 8.71 & 5.08 & 4.67 & 5.19 & 9.00 & 4.99 & - & 5.29 & - & 4.92 \\
QT20 & 5.10 & 17.44 & 5.06 & 14.58 & 5.47 & 6.43 & 6.33 & 5.72 & 8.26 & 5.67 \\
\hline
\end{tabular}

Note-The programmed schedules were concurrent VR 5 schedules with response requirements ranging from 1 to 16 presses. Italicized values represent cases in which fewer than 10 reinforcers, on average, were obtained. "-" indicates cases in which no reinforcers were obtained on that alternative. 
the shorter alternative decreased toward $0 \mathrm{sec}$, behavior shifted toward the longer alternative. At $2.5 \mathrm{sec}$ and below, response allocation, averaged across all animals, favored the longer alternative. Above $2.5 \mathrm{sec}$, response allocation averaged out to indifference. However, it is important to note that indifference, in this case, resulted from averaging across animals, with allocations favoring one alternative or the other, rather than animals favoring neither.

Although the duration of both reinforcers varied, it is unlikely that the observed shifts in allocation were a function of the modest lengthening of the longer duration. Instead, it is more likely that the observed shift in behavior allocation was a function of the progressive shortening of the shorter duration toward $0 \mathrm{sec}$.

The ratio of reinforcer durations also became more extreme as the durations changed, and this suggests the possibility that relative allocation was affected by relative duration. In the initial $50-10 \mathrm{sec}$ condition, the ratio was $5: 1$. As durations changed across values of $55-5 \mathrm{sec}$, $57.5-2.5 \mathrm{sec}, 58.75-1.25 \mathrm{sec}$, and $59.5-0.5 \mathrm{sec}$, the ratio of durations changed across values of 11:1, 23:1, 47:1, and 119:1. A problem for this explanation is that preference for the longer duration was not observed until the ratio was $23: 1$.

\section{GENERAL DISCUSSION}

The present studies gave rise to two findings that need to be explained. The first is the lack of a systematic preference between 10-sec and 50-sec opportunities to run. The second is the shift in behavior allocation toward the longer reinforcer, as the shorter duration alternative was progressively shortened. It is important to note that the indifference in choice between $10 \mathrm{sec}$ and $50 \mathrm{sec}$ was an averaged result. At the level of individual animals, allocations favoring both alternatives were evident. It is likely that these observed "preferences" reflected side biases rather than control by the reinforcer associated with that alternative. Such side biases should average out over animals. Exposure to the different durations did not produce a systematic preference for either alternative; consequently, reversing the durations did not yield a systematic shift in preference. This suggests that the difference in duration had less impact on how animals distributed their responses between the alternatives than did extraneous variables that generated side biases.

In order for a systematic preference for an alternative to develop, the animal must discriminate the difference between the two alternatives and associate the difference with the two alternatives. If either fails to occur, indifference should result. Research on temporal perception in animals using fixed-interval schedules (see, e.g., Lejeune $\&$ Wearden, 1991) and the peak procedure (Roberts, 1981) shows that animals can accurately time intervals shorter than $10 \mathrm{sec}$ and longer than $50 \mathrm{sec}$. More important, duration discrimination studies (Church, Getty, \& Lerner, 1976; Crystal, 1999; Roberts \& Church, 1978) show that rats can accurately discriminate between stimulus events of different durations that are as long as those used in the present study (see, e.g., Crystal, 1999). Thus, it seems unlikely that the animals cannot perceive the difference in durations.

With respect to the latter requirement, an experiment with pigeons by Killeen and Smith (1984) may be relevant. Food reinforcers would occasionally follow responses on an illuminated center key; at other times, food reinforcers would occur independently of the pigeon's behavior. Following the termination of a reinforcer, side keylights would go on. If the reinforcer had occurred as a consequence of the pigeon's behavior, a peck on the right key produced an additional 2.5-sec food reinforcer. A peck on the left key produced an equivalent duration of blackout. If the reinforcer occurred independently of the pigeon's behavior, a response on the left key produced an additional food reinforcer. A peck on the right key produced blackout. The dependent variable was the accuracy of attributing the center key reinforcer as dependent or independent of its behavior.

In the experiment, the duration of the center key reinforcer was varied across values of $1,2,3$, and $4 \mathrm{sec}$. The results showed that as the duration of the center key reinforcer increased, accuracy decreased from a value greater than .8 at $1 \mathrm{sec}$ to a value close to .5 at $4 \mathrm{sec}$. Accuracy fell to chance level. In a comparison condition, the duration of illumination of the hopper light without hopper activation was varied. In this comparison condition, as light duration increased, accuracy decreased from a value greater than .8 to a value close to .73 . In sum, accuracy declined to chance when the animals were engaged in consummatory behavior, but only marginally when the animals were not. Engaging in consummatory behavior adversely affected the animals' ability to accurately attribute the source of the consequence.

Extrapolating from Killeen and Smith's (1984) results to the present study suggests the possibility that indifference to the two durations tested may be a function of an inability to associate the durations with their respective alternatives. Ten-sec and 50-sec reinforcers do not differ until $10 \mathrm{sec}$ has elapsed. At that point in time, the occurrence of the event that differentiates the two reinforcers (i.e., onset of the brake at $10 \mathrm{sec}$ vs. $50 \mathrm{sec}$ ) is temporally remote from the response that initiated the running period, and a number of revolutions have been run. These revolutions may contribute to a memory erasure effect that diminishes association with the response that produced that particular opportunity to run. If this is the case, then the animal should be insensitive to any differences in durations in which the time intervals on both alternatives are long, because the differences would not be associated with the behaviors that produce the reinforcer. However, if the duration of one of the alternatives is sufficiently short so that the onset of the brake on the shorter alternative is associated with the response that initiated the running period, then the animal should be sensitive to the difference in durations. This would account for both the lack of an effect for 10 and $50 \mathrm{sec}$ and the shift away from the shorter duration as duration decreased toward $0 \mathrm{sec}$. However, the observation that some animals markedly increased their 


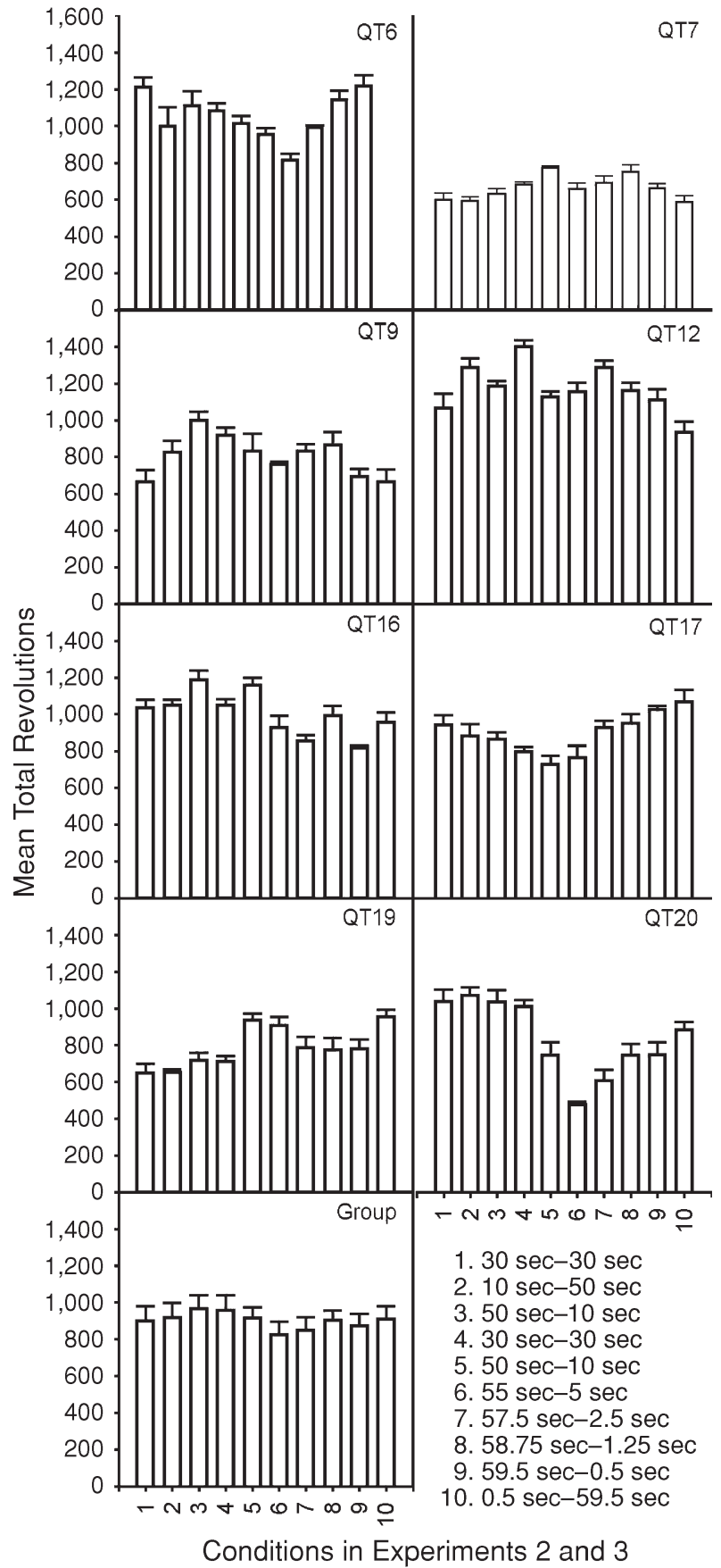

Figure 4. Mean total revolutions in each condition of Experiments 2 and 3 for each animal and the group. Standard errors are depicted.

rate of responding on an alternative when the duration associated with that alternative decreased from 30 to $10 \mathrm{sec}$ suggests sensitivity to this change in duration.

Alternatively, it is possible that the animals are insensitive to local differences in duration because their behavior is being regulated at a different level. Animals are thought to "defend" or maintain their level of running as part of the regulation of total energy output (Collier \& Hirsch,
1971; Sherwin, 1998). Figure 4 shows total revolutions for each animal in each condition in Experiments 2 and 3. On average, total revolutions remained relatively constant, even though the durations associated with the two alternatives varied considerably. This explanation also accommodates individual differences with respect to how animals responded to changes in the duration associated with an alternative. Total revolutions could be maintained by either reallocating behavior toward the longer duration, by markedly increasing the rate of obtained reinforcement on an alternative in which duration decreased, by adjusting their rate of running during reinforcers, or by some combination of the aforementioned. As duration on the shorter alternative was progressively shortened, reallocation would be the only way to maintain total revolutions. However, the observation that some animals markedly increased their response rate on an alternative when duration was decreased also presents a problem for this explanation, because they did so within the first session, before experiencing an effect of the change in duration on total revolutions.

Future research should investigate the conditions required to demonstrate a systematic preference between reinforcers of different durations. One issue is the role of relative and absolute duration values. Logue and Chavarro (1987) showed that preference between food reinforcers of different durations diminished as the absolute duration of access increased while the relative ratio of durations remained constant. With respect to wheel running, animals could be exposed to concurrent schedules of wheelrunning reinforcement with reinforcer duration pairs of $2.5-12.5 \mathrm{sec}, 5-25 \mathrm{sec}$, and $10-50 \mathrm{sec}$. Given the observed preferences in the present study, one would expect animals to show a preference for the longer duration in the shortest duration pair. One would also expect that the strength of that preference would diminish toward indifference as the durations lengthened.

In summary, the assumption that a difference in wheelrunning reinforcer durations can be conceptualized to be like a difference in access to food was not supported. No systematic preference for the longer reinforcer occurred until the duration on the other was less than $5 \mathrm{sec}$. At longer durations, the difference in durations affected choice less than extraneous variables generating side bias. Further investigation will be required to learn why differences in duration do not affect choice.

\section{REFERENCES}

Allison, J. (1993). Response deprivation, reinforcement, and economics. Journal of the Experimental Analysis of Behavior, 60, 129-140.

BELKE, T. W. (1997). Running and responding reinforced by the opportunity to run: Effect of reinforcer duration. Journal of the Experimental Analysis of Behavior, 67, 337-351.

Belke, T. W., \& Belliveau, J. (2001). The generalized matching law describes choice on concurrent variable-interval schedules of wheelrunning reinforcement. Journal of the Experimental Analysis of Behavior, 75, 299-310.

Belke, T. W., \& Dunbar, M. (1998). Effects of fixed-interval schedule and reinforcer duration on responding reinforced by the opportunity to run. Journal of the Experimental Analysis of Behavior, 70, 69-78. 
Belke, T. W., \& Hancock, S. D. (2003). Responding for sucrose and wheel-running reinforcement: Effects of sucrose concentration and wheel-running reinforcer duration. Journal of the Experimental Analysis of Behavior, 79, 243-265.

Belke, T. W., \& McLaughlin, R. J. (2005). Habituation contributes to the decline in wheel running within wheel-running reinforcement periods. Behavioural Processes, 68, 107-115.

Bonem, M., \& Crossman, E. K. (1988). Elucidating the effects of reinforcement magnitude. Psychological Bulletin, 104, 348-362.

Catania, A. C. (1963). Concurrent performances: A baseline for the study of reinforcement magnitude. Journal of the Experimental Analysis of Behavior, 6, 299-300.

Church, R. M., Getty, D. J., \& Lerner, N. D. (1976). Duration discrimination by rats. Journal of Experimental Psychology: Animal Behavior Processes, 2, 303-312.

Collier, G., \& Hirsch, E. (1971). Reinforcing properties of spontaneous activity in the rat. Journal of Comparative \& Physiological Psychology, 77, 155-160.

Crystal, J. D. (1999). Systematic nonlinearities in the perception of temporal intervals. Journal of Experimental Psychology: Animal Behavior Processes, 25, 3-17.

EPSTEIN, R. (1981). Amount consumed as a function of magazine-cycle duration. Behaviour Analysis Letters, 1, 63-66.

Harzem, P., Lowe, C. F., \& Priddle-Higson, P. J. (1978). Inhibiting function of reinforcement: Magnitude effects on variable-interval schedules. Journal of the Experimental Analysis of Behavior, 30, 110.

Herrnstein, R. J., \& Loveland, D. H. (1975). Maximizing and matching on concurrent ratio schedules. Journal of the Experimental Analysis of Behavior, 24, 107-116.

HutT, P. J. (1954). Rate of bar pressing as a function of quality and quantity of food reward. Journal of Comparative \& Physiological Psychology, 47, 235-239.

Jenkins, W. O., \& Clayton, F. L. (1949). Rate of responding and amount of reinforcement. Journal of Comparative \& Physiological Psychology, 42, 174-181.

KeEsey, R. E., \& KLING, J. W. (1961). Amount of reinforcement and free-operant responding. Journal of the Experimental Analysis of Behavior, 4, 125-132.

Killeen, P. R., \& Smith, J. P. (1984). Perception of contingency in conditioning: Scalar timing, response bias, and erasure of memory by reinforcement. Journal of Experimental Psychology: Animal Behavior Processes, 10, 333-345.

Kliner, D. J., Lemaire, G. A., \& Meisch, R. A. (1988). Interactive effects of fixed-ratio size and number of food pellets per fixed ratio on rats' food-reinforced behavior. Psychological Record, 38, 121-143.

LeJeune, H., \& Wearden, J. H. (1991). The comparative psychology of fixed-interval responding: Some quantitative analyses. Learning \& Motivation, 22, 84-111.

Logue, A. W., \& Chavarro, A. (1987). Effect on choice of absolute and relative values of reinforcer delay, amount, and frequency. Journal of Experimental Psychology: Animal Behavior Processes, 13, 280-291.

Lowe, C. F., Davey, G. C., \& Harzem, P. (1974). Effects of reinforcement magnitude on interval and ratio schedules. Journal of the Experimental Analysis of Behavior, 22, 553-560.

Meltzer, D., \& BrahleK, J. A. (1968). Quantity of reinforcement and fixed-interval performance. Psychonomic Science, 12, 207-208.

Meltzer, D., \& Brahlek, J. A. (1970). Quantity of reinforcement and fixed-interval performance: Within-subject effects. Psychonomic Science, 20, 30-31.

Powell, R. W. (1969). The effect of reinforcement magnitude upon responding under fixed-ratio schedules. Journal of the Experimental Analysis of Behavior, 12, 605-608.

Priddle-Higson, P. J., Lowe, C. F., \& Harzem, P. (1976). Aftereffects of reinforcement on variable-ratio schedules. Journal of the Experimental Analysis of Behavior, 25, 347-354.

REED, P. (1991). Multiple determinants of the effects of reinforcement magnitude on free-operant response rates. Journal of the Experimental Analysis of Behavior, 55, 109-123.

ReED, P., \& Wright, J. E. (1988). Effects of magnitude of food reinforcement on free-operant response rates. Journal of the Experimental Analysis of Behavior, 49, 75-85.

RoBERTS, S. (1981). Isolation of an internal clock. Journal of Experimental Psychology: Animal Behavior Processes, 7, 242-268.

Roberts, S., \& CHurch, R. M. (1978). Control of an internal clock. Journal of Experimental Psychology: Animal Behavior Processes, 4, 318-337.

Sherwin, C. M. (1998). Voluntary wheel running: A review and novel interpretation. Animal Behaviour, 56, 11-27.

Shull, R. L. (1970). A response-initiated fixed-interval schedule of reinforcement. Journal of the Experimental Analysis of Behavior, 13, $13-15$.

Staddon, J. E. (1970). Effect of reinforcement duration on fixedinterval responding. Journal of the Experimental Analysis of Behavior, 13, 9-11.

Stebbins, W. C., Mead, P. B., \& Martin, J. M. (1959). The relation of amount of reinforcement to performance under a fixed-interval schedule. Journal of the Experimental Analysis of Behavior, 2, 351-355.

Timberlake, W., \& Allison, J. (1974). Response deprivation: An empirical approach to instrumental performance. Psychological Review, 81, 146-164.

(Manuscript received January 7, 2005; revision accepted for publication April 25, 2005.) 